\title{
O SOFRIMENTO: PAIXÃO PELO PARADOXO DO ABSOLUTO DESESPERO E ANGÚSTIA NA OBRA DE KIERKEGAARD.
}

\author{
Marcos da Silva e Silva*1 \\ Pontifícia Universidade Católica de São Paulo. (PUC-SP) \\ Freemarcos1@yahoo.com.br
}

\section{Resumo}

Pretendemos abordar o conceito de Sofrimento, apresentados nas obras de Sören Aabye Kierkegaard (1813 - 1855): O Desespero Humano (Doença Mortal) 1849, e O Conceito de Angústia 1844. A criação deste autor tem a necessidade de estar sempre presente. A busca do conhecer, nos põe no labirinto espelhado do conhecer-se e não perde-se no caminho do procurar-se. Procurar-se é angustiar-se, conhecer-se é desesperar-se frente ao sofrer. 0 sofrimento humano suscita paixão e esta se relaciona ao patético e ao dialético na vida humana. O patético está em primeiro lugar, pois, por meio dele, culmina a paixão pela felicidade eterna do homem em busca da interioridade existencial. Neste sentido existir é encontrar-se vinculado ao Absoluto, é uma condição necessária da qual não se pode escapar, pois a impulsão que leva o homem a existir o leva a saltar, a aceitar o sofrimento de forma absurda. Discutir esses conceitos é tornar latentes os silêncios existências. Por esse motivo buscamos um diálogo com Kierkegaard como possibilidade de aprofundar os debates sobre o sofrimento humano.

Palavras Chave: Sofrimento; Desespero; Angústia.

\section{O Sofrimento: Paixão Pelo Paradoxo Do Absoluto.}

O sofrimento humano suscita paixão e esta se relaciona ao patético e ao dialético na vida humana. O patético está em primeiro lugar, pois, por meio dele, culmina a paixão pela felicidade eterna do homem em busca do Absoluto. "Assim, tal como a falta é intensificada, o paradoxo da fé é, necessariamente, acompanhado de angústia e tribulações". (PAULA, 2001, p. 119). Trata-se de uma característica da interioridade existencial

Assim se refere Kierkegaard:

(*) Marcos da Silva e Silva. Capítulo da dissertação de mestrado em Filosofia. 
Um problema existencial tem um duplo aspecto: o patético e o dialético. Assim, o problema aqui tratado exige a interioridade existencial para agarrar o patético, a paixão para agarrar o dialético, e a paixão intensa pelo qual devemos existir nesta questão. (KIERKEGAARD. 2008, p. 16)

Pode-se dizer que o homem torna-se o caminho da afirmação de si, o sofrimento conduz à subjetividade por meio da paixão pelo telos Absoluto sem temer o paradoxo da fé. Porém, "a fé é a paixão perseverante da existência no tempo". Valls faz a seguinte observação:

Uma terceira possibilidade de se compreender a subjetividade é quando Climacus a define no interior da interioridade como verdade, e esta como paixão. A subjetividade se traduz como paradoxo. Segundo Kierkegaard: “o ápice da interioridade em um indivíduo é a paixão, à paixão corresponde a verdade como paradoxo; o fato de que a verdade se torna paradoxo é fundado precisamente na relação com o sujeito existente". A paixão "é o máximo da subjetividade," porém, a mais alta paixão do homem é a fé. (ALMEIDA, 2007, P. 56)

A verdade como paradoxo é a paixão necessária para a subjetividade; isso acontece em diversos momentos da vida, de diversas maneiras, em dimensões diferentes, mas de uma forma ou de outra, o sofrimento parece ser, e é mesmo, inseparável da existência do homem, pois a paixão o intermedia. Este intermédio - o sofrimento - indica em quais momentos 0 indivíduo passa a existir mediante a paixão. É um meio de comunicação com o paradoxo do Absoluto, que intensifica a existência do homem em um sofrimento apaixonado.

Existem duas maneiras pelas quais o existente pode estar fora da existência que não levam à mediação. Uma consiste em fazer a mediação de si mesmo, adquirindo a indiferença e a ataraxia do cético. A outra consiste em existir na paixão; mas no momento da paixão, o indivíduo recebe uma impulsão que o leva precisamente a existir. (FARAGO. 2006, p. 173).

Neste sentido existir é encontrar-se vinculado ao Absoluto, é uma condição necessária da qual não se pode escapar, pois a impulsão que leva o homem a existir o leva a saltar, a aceitar o sofrimento de forma absurda:

A entrada de Deus no tempo, na história, provocou o paradoxo, pois a razão não consegue reunir a ideia de um Deus eterno com a figura deste servo humilde. O princípio de identidade fracassa; sobra a opção salto da fé, renunciando, neste ponto, à inteligência. Ante o paradoxo, ante o "fato do Absoluto", o contemporâneo, que se serve dos sentidos para reconhecer o fenômeno, não possui nenhum frente aos pósteros. (KIERKEGAARD. 2008, p. 16)

A existência que é mediada pela paixão, não é uma existência vazia; a impulsão que leva o homem a existir não elimina o sofrimento, o faz compreender-se, já o "salto da fé", comunica um escândalo, como pontuamos o escândalo do Absoluto. Assim, o homem sofre por não compreender o paradoxo, já que oscila por estar frente ao abismo: 
Mais uma vez, nos fala Johannes Climacus:

Consequentemente, porém, aqueles que se constroem sobre um paradoxo são, afinal, humanamente falando, edificantes sobre o abismo, e o conteúdo total das consequências, que só se transmite ao indivíduo sob a concordância de que elas ocorrem em virtude do paradoxo, é claro que não deve ser tomado como um bem estável, já que tudo é flutuante. (KIERKEGAARD. 2008, 140)

Não obstante, o paradoxo intensifica no homem a sua existência, mesmo que seja absurdo, por ser a existência mediante a fé. Sendo o sofrimento parte integrante da existência, e estando no momento paradoxal da fé, o sofrimento é digno de respeito e, a seu modo, intimida. O homem, em seu sofrimento, permanece um mistério inteligível, porque o sofrimento é incomunicável e silencioso.

\section{O Sofrimento Silencioso Como Paradoxo Da Comunicação Indireta: O Silêncio De Abraão,} Sinônimo Paradoxal Da Fé.

É importante destacar, como ficou exposto acima, que Kierkegaard assinala, ainda, a existência de um terceiro estádio, a saber, a vida religiosa, apresentada na seção do livro "Ou...Ou...", intitulada "Ultimatum", onde, para o homem religioso, a vida é sofrimento. O estádio religioso, isto é, o momento onde o sofrimento é intensificado, implica uma devoção para com Deus, por meio do silêncio e da solidão.

A solidão² no sofrimento torna-se, por conseguinte, o centro das reflexões, a partir das quais o filósofo desenvolve o sentido da subjetividade e da existência. Apenas o sofrimento vivido continuamente força o homem a viver na solidão, que o conduz a descobrir o valor de sua individualidade, encontrando, enfim, a reconciliação com ele mesmo a partir da reconciliação absoluta com Deus. "Este pensamento que temos sempre vividamente frente a Deus, pára a dúvida e apazigua sua inquietude; ele encoraja e leva à ação" (KIERKEGAARD. 2008, p. 606) porque a ação silenciosa afirma que a comunicação deve ser indireta com o Outro, por meio do homem que a pratica.

\footnotetext{
${ }^{2}$ E este ultimo desejo é decerto o melhor, porque a solidão sent-se quando se ouve os outros afastarense . No Don Juan a mais solitária das situações é a de Zerlina; Zeerlina não está só, antes vai ficando só; ouve-se o coro desaparcer, e, no progressivo desaparecimento desse som na distancia, a solidão tornase audível, torna-se presente: vós Oito Caminhos, haveis simplismente afastado de mim toda a gente, e haveis-me restituído somente os meus próprios pensamentos. KIERKEGAARD S.A. In Vino Veritas. Trad.José Miranda Justos. Antígona. 2005. p. 32.
} 
Na sua dimensão subjetiva, como fato pessoal na existência, no íntimo do homem, o sofrimento parece ser algo quase inefável e incomunicável, pois é uma comunicação orante, não apenas tagarelices.

A comunicação orante, por meio da ação, não se limita apenas àquele que ouve, mas atinge a interioridade de quem fala; neste sentido, a oração silenciosa é a unificação da alma com a ação subjetiva e o Inteiramente Outro. Parafraseando-se Farago, pode se dizer o seguinte: "Assim, a inabitação de Deus no silêncio, a verdadeira oração se reduz a 'ouvir'”. A verdadeira oração nada tem a ver com o requerimento ou com a reivindicação. O orante não é um mendigo. Fitando o mistério com os próprios olhos da sombra, faz-se receptivo ao eco da verdade, que vai abrindo caminho no próprio coração do silêncio. Vem a luz, então, iluminar os olhos da fé. Esta é a "Palavra" de Deus, para além dos sermões ou das tagarelices paroquiais, palavra silenciosa, interior, aquém das palavras, que dá o tom exato à palavra humana que venha falar em seu Nome e lhe confere o princípio de sua compreensão.

Kierkegaard não ignora que é necessário, também, mortificar essas palavras, sua imediatidade à qual se soma a inflação de uma repetição infindável, para alcançar o seu referente infrassimbólico, anterior a toda linguagem. É possível, então, no silêncio reencontrado, ouvir novamente o verbo inaudível aos surdos, ver a luz invisível para os cegos de nascença que não querem a cura de sua cegueira. Tudo se pode ouvir novamente. A miséria do espírito pode recuar, porque a fonte de vida comum a todos se deixa ouvir e tocar, quando tudo se cala. Somente estas núpcias do espírito com o silêncio de Deus permitem a cada pessoa nascer para sua mais profunda singularidade, para sua unicidade, longe do mimetismo do rebanho, que só produz artefatos de personalidade. O silêncio é reunião, unificação de si mesmo, sinal da síntese com gênese. "Se você verdadeiramente unificou sua alma, está no 'silêncio'". O silêncio permite pacificar as paixões muito perturbadoras, que deixam o coração febril.

Cresce a tranquilidade à medida que cresce a sombra, à medoda que cresce o silêncio: poderosa fórmula mágica! De facto, que coisa será tão inebriante como a tranquilidade! Pois, por mais depressa que o bebedor leve a taça a boca, a sua embriaguez não cresce tão subtamente quanto a da tranquilidade que aumenta a cada segundo que passa! E que é o conteúdo da taça embreagante senão uma gota em comparação com o infindável oceano de silêncio do qual bebo! E o que é a infevescência do vinho senão miserável embuste em comparação com a fermetação do silêncio que ferve com vigor sempre maior! (KIERKEGAARD. 2005, p. 29)

É a prece agônica que arranca do divertimento da contingência para enraizar no único necessário: a refontalização na origem que regenera as almas exangues ou agitadas. A fé 
surge, assim, em Kierkegaard, como um combate solitário, a aventura da relação singular de si mesmo com Deus, que nenhum outro, a não ser nós mesmos, pode fazer em nosso lugar.

Assim é o sofrimento de Abraão, em "Temor e Tremor", onde Kierkegaard/Johannes de Silentio nos fala, na "Atmosfera", da prova de Abraão. Nesse momento, o sofrimento é silencioso, pois trata-se do salto da fé, no limite entre o estádio ético e o estádio religioso, não permitindo, assim, um refúgio fora do sofrimento. É mais do que um mero calar-se, é uma comunicação da verdade, a verdade que Abraão descobre no silêncio da subida do Monte Morija.

Abraão não pode falar, porque se trata de uma relação pessoal do indivíduo com o Inteiramente Outro. O sofrimento de Abraão é silencioso. A atmosfera de "Temor e Tremor" retrata esse sofrimento pelos sacrifício de Isaac pelo seu pai Abraão e a caminhada silenciosa até a montanha de Morija.

O silêncio de Abraão não é um silêncio qualquer, é o silêncio da escolha (KIERKEGAARD. 2008, p. 8) no limite entre o estádio ético e o estádio religioso. O que não se pode excluir neste silêncio é o sofrimento que se comunica pela escolha que Abraão tem que fazer, e isso implica uma certa medida de sofrimento, pois é singular, é uma escolha pela paixão, é interior ao homem, é uma escolha que Abraão faz enquanto caminha na solidão do monte Morija.

\section{Silêncio: Solidão Interior Não-Hermética.}

O sofrimento emerge como sinônimo de desespero interior, em certo momento hermético, um estado de solidão interior, mas que em seu princípio não é hermética, pois não se encontra no desespero demoníaco, como pontua Kierkegaard, em "Temor e Tremor". O silêncio imposta-se na intensificação da possibilidade do indivíduo que escolhe por si, que faz a sua escolha e só comunica-se de maneira silenciosa, consigo mesmo. Exprime-se uma verdade interior, de angústia, de sofrimento ou de medo é o desespero silencioso.

Esta condição silenciosa torna o sofrimento do homem incomunicável, pois não há linguagem e é uma comunicação indireta de uma interioridade ao Absoluto, a uma interioridade, como uma oração. O silêncio é autocentrado, autocrático, sinônimo de uma solidão que escapa à alçada do outro.

Por outro lado, muito frequentemente uma necessidade de solidão o invade, tão vital para ele como respirar ou dormir. Que ele tenha essa necessidade vital mais que as pessoas comuns, é uma mostra de uma natureza mais profunda. A necessidade de solidão é prova sempre em nós de espiritualidade e serve para medi-la. (KIERKEGAARD, 2008, p. 412) 
Não obstante, a felicidade eterna é contemplada pelos amantes da solidão e o silêncio é o que conduz a esse encontro fora de si, contudo, está fora de si porque é uma condição necessária para aceitar o sofrimento.

Pelo sofrimento, o indivíduo revela-se num "outro" e, neste momento, cujo silêncio é religioso. Quanto mais profundo for o sofrimento pelo silêncio e pela solidão, maior será a distância que nos separa do mundo para um duplo esforço: sair de si, transcender-se como condição para regressar a si. O descentrar-se, saltar, retornar a si mesmo, mediado pelo silêncio e pela solidão, configura um salto que só o indivíduo, na constituição do seu "eu", pode fazer.

Na realização do salto sou - não o mesmo, mas um outro enriquecido por este esforço de interiorização. O salto sucede a imanência do "eu". Mas o "eu" tende a desesperar-se, chegando, como ficou dito acima, a um hermetismo, ao "desespero demoníaco". Temos de deixar claro o que vem a ser o hermetismo, para que este não seja confundido com o silêncio.

\section{O Hermetismo: Desespero Demoníaco}

Kierkegaard compara o hermetismo a uma porta falsa, atrás da qual nada existe e está cuidadosamente fechada. É atrás dessa porta que o "eu" do desesperado se esconde e esse isolamento apresenta-se num duplo movimento: a recusa de ser si mesmo e o amor autodirecionado, tal como Kierkegaard/Anti-Climacus diz:

Esse desespero de um grau mais elevado que o anterior é daqueles que encontramos com menos frequência no mundo. Esta porta condenada, atrás da qual não havia nada mais que o Nada, é aqui uma verdadeira porta, mas outrora trancada, e, atrás dela, o eu, atento a ele mesmo, se ocupa e passa o tempo a negar de ser ele mesmo, fazendo pouco caso de se amar. É o que chamamos "hermetismo", do qual vamos nos ocupar agora, este contrário do espontâneo puro, que ele despreza por fraqueza intelectual. (KIERKEGAARD, 2008, p. 411)

Segundo Kierkegaard, o desesperado está tão fechado em si mesmo que mantém todos à distância de seu "eu". Frequentemente, experimenta um desejo de estar só, que é uma necessidade vital, quase como respirar. Ele vive, no seu hermetismo, horis successivis, horas que, ainda que não sendo vividas para a eternidade, têm a ver com o eterno: ele se ocupa da relação do seu eu consigo mesmo. Mas, este homem não vai além disso, porque o seu desejo de solidão não deve ser considerado como signo de um espírito mais profundo, avesso à tagarelice, à companhia desses "tagarelas que nada têm de humano e só podem viver acompanhados". O seu hermetismo é orgulho, o orgulho de desesperar da própria fraqueza. 0 desespero hermético conserva-se no distanciamento do homem com seu próprio "eu". 
Todo "eu", ainda que seja pouco refletido, possui, entretanto, a ideia de se dominar. E nosso desesperado possui hermetismo suficiente para manter os importunos, isto é, todo mundo, à distância dos segredos de seu eu, sem perder o aspecto de um ser vivo. (KIERKEGAARD, 2008, p. 411-412)

O hermetismo atinge o homem mais simples. Caso esse homem, por alguma revolução, não se ponha no caminho da fé, seu desespero, ou se eleva em potência até uma forma mais alta em que continua a ser hermetismo, ou se rompe, destruindo o disfarce exterior sob o qual este desesperado viveu incógnito. No primeiro caso, quando o desespero se condensa, transforma-se em desafio, e podemos ver a falsidade do desespero que se diz fraqueza; vê-se, com evidência, como é dialeticamente exato dizer que a primeira expressão do desafio é justamente o desespero a respeito de sua fraqueza. No segundo caso, ele se lançará na existência, distraindo-se com grandes empreendimentos e se tornará um espírito inquieto em busca do esquecimento, ou buscará o esquecimento na sensualidade, talvez na libertinagem, para, em seu desespero, regressar à imediatidade, mas sempre com a consciência do "eu" que ele não quer ser.

Se esse desesperado mantém seu hermetismo intacto, omnibus numeris absoluta, o perigo iminente é o suicídio. Ou seja, o de não aceitar o sofrimento. Se ele possuir um só confidente, experimentará tal alívio que haverá probabilidade de se evitar o suicídio. Mas, pode acontecer que a confidência dê lugar ao desespero e, então, lhe parecerá que teria sido melhor o silêncio:

Mas, lancemos um último olhar no fundo deste taciturno, não faz se não pisar em sua taciturnidade. Se ele a mantém intacta, omnibus numeris absoluta, o suicídio é seu primeiro risco. 0 comum dos homens não tem naturalmente a menor desconfiança do que um tal hermético pode suportar; eles ficariam estupefatos de o saber. Tanto isso é verdade que ele se arrisca ao suicídio, antes de tudo. Que ele diga a alguém o contrário, que ele se abra a uma pessoa, e é então nele, quase uma certeza, um tal relaxamento, um tal apaziguamento, que o suicídio deixa de ser a saída do hermetismo. Um confidente já, um só, é suficiente para abaixar em um tom o hermetismo absoluto. O suicídio tem chances, então, de ser evitado. Mas a própria confidência pode mesmo dar lugar ao desespero, hermético vê então, teria sido infinitamente melhor suportar a dor de se calar, do que tomar um confidente. Temos exemplos de herméticos levados justamente ao desespero pelo fato de terem tido um. O suicídio pode, então, apesar de tudo, acontecer. (KIERKEGAARD, 2008, p. 414)

O hermetismo levaria ao suicídio por não haver comunicação para o homem hermético; o seu sofrimento não pode ser comunicado, não há um confidente. Esse hermetismo é diferente de um poeta. Para um poeta, essa contradição dolorosa de um 
espírito demoníaco, incapaz tanto de ter um confidente quanto de passar sem ele, poderia expressar-se no tema do déspota demoníaco que mataria, sucessivamente, seus confidentes.

A revelação de seu segredo causaria angústia, já não seria o mesmo, e não haveria aprofundamento; a angústia estaria mascarada em suas revelações, seu sofrimento é agora visto, não mais sentido.

Toda a interiorização conduz ao aprofundamento e este só é possível porque o mundo nos angustia. Mas não são as ideias que permitem acender a esta interiorização, é o sofrimento. Talvez nenhuma outra coisa exija ao mesmo tempo tanto como ele - na sua realidade subjetiva a ser tratada, meditada e concebida, dando ao problema uma forma explícita. É daí que a seu respeito se levantem questões de fundo e que para estas se procure uma resposta.Assim, como é tratado de uma maneira subjetiva, o sofrimento humano, quando não comunicado, não é determinado por um tempo ou estágio de tempo, pois é inerente à temporalidade, "é a interioridade no homem”, não escapa a ele, é um refúgio poético.

O homem que não entende o seu sofrimento, mesmo que seja de maneira poética, que busca satisfação estética, descobre-se numa autorrealização efêmera. Nela, o indivíduo não tem consciência de seu sofrimento, pois não o vivencia, ludibriado por uma felicidade imediata e poética que camufla o pathos do sofrimento. "O indivíduo deve, portanto, tentar perseverar no sofrimento, a fim de se encontrar por meio dele e não fazer como o poeta que cria obras pelo sofrimento sem, todavia, assumir o dever de se compreender por meio dele. Sob esse ângulo, a obra do poeta é, precisamente, uma fuga diante do sofrimento". Ainda, no post-scriptum aux Miettes philosophiques, encontramos o seguinte:

\footnotetext{
Que, por exemplo, o poeta não se deixa influenciar por sua própria produção poética, esta de acordo do ponto de vista estético; ou completamente indiferente, porque, esteticamente, a produção poética e a possibilidade são o plano mais elevado. Mas, eticamente, é ao contrário da mais extrema importância, porque eticamente, a vida do poeta é completamente indiferente, enquanto que sua própria existência deve ser o que há de mais importante para ele. (KIERKEGAARD, 2008, p. 329-330)
}

O sofrimento humano pode ser explorado de modo mais amplo a partir da tragédia, pois não se prende ao hermetismo e, desde os gregos, e em certa medida até o nosso tempo, foi a forma objetiva de comunicar o sofrimento, e da maneira como ele se propagou no decorrer da história, tornando-a trágica, tendo em vista que o sofrimento ganha um sentido frio frente a ação humana.

\section{Referências Bibliográficas.}


ALMEIDA, J. M. de; VALLS, A. L. M. Kierkegaard: filosofia passo-a-passo. Rio de janeiro: Jorge Zahar, 2007, 78p.

KIERKEGAARD, S. A. Discours chrétienes. La soucis des païens, Sentiments dans la lutte des souffrances, Les pensées qui blessent... pour édifier, Discours pour la communion. Trad. de. P. H. TISSEAU. Delachaux et niestlé.

Étapes sur le chiming de la vie. Trad. de F. Prior ET M. H. Guignot. Paris: Éditions Galimard, 1948, 592p.

In Vino Veritas. Trad. de José Miranda Justos. Antígona, 2005.

La Répeticion, Craint et Treblement, 1846. Trad. de Tisseau, Paul Henri et JacqueTisseau, Else-Marie, Paris: Éditions de L'orante, 1972.

Le Journal Du Séducteur. Trad. de F. Prior ET M.- H. Guignot. Paris: Éditions Galimard, 1948, 592p.

Miettes philosophiques. Le concept de l'angoisse Traité du désespoir. Gallimard, 2008. Vozes, 1995.

Migalhas filosóficas ou um bocadinho de filosofia de João Clímacos. Petrópolis:

O conceito de angústia. Trad. de João Lopes Alves. Lisboa: Editorial presença. 1972, $224 p$.

. O conceito de ironia constantemente referido a Sócrates. Apresentação e tradução de Álvaro Luiz Montinegro Valls. Petrópolis: Vozes, 1991, 283p.

Ou Bien ou Bien. Le reflet du tragique ancien sur lê moderne. Gallimard, 2008.

Poit de vue explicatiff de mom ouvre d'esrivan, Duex petits traités éthicoreligieux. La maladie e La Morte, six dicours, 1848-1849. Trad. de Tisseau, Paul Henri et Jacque-Tisseau, Else-Marie, Paris: Éditions de L'orante, 1980.

Post-Scriptum aux Miettes philosophiques. Le pathétique. Tel Gallimard, 2008.

. Temor e tremor. Humus. Trad. de. Torriere Guimarães, 2008.

VALLS, A. L. M. Do desespero silencioso ao elogio do amor desinteressado. Aforismos, novelas e discursos de Soren Kierkegaard (organizador, tradutor e apresentador). Porto Alegre:

Escritos, 2004, 104p. 